\title{
CORIUM BEHAVIOR IN THE LOWER PLENUM OF THE REACTOR VESSEL UNDER IVR-ERVC CONDITION: TECHNICAL ISSUES
}

\author{
RAEJOON PARK*, KYOUNGHO KANG, SEONGWAN HONG, SANGBAIK KIM, and JINHO SONG \\ Korea Atomic Energy Research Institute \\ 1045 Daedeok-daero, Yuseong-gu, Daejeon, 305-353, Korea \\ "Corresponding author. E-mail : rjpark@kaeri.re.kr
}

Received March 28, 2012

Corium behavior in the lower plenum of the reactor vessel during a severe accident is very important, as this affects a failure mechanism of the lower head vessel and a thermal load to the outer reactor vessel under the IVR-ERVC (In-Vessel corium Retention through External Reactor Vessel Cooling) condition. This paper discusses the state of the art and technical issues on corium behavior in the lower plenum, such as initial corium pool formation characteristics and its transient behavior, natural convection heat transfer in various geometries, natural convection heat transfer with a phase change of melting and solidification, and corium interaction with a lower head vessel including penetrations of the ICI (In-Core Instrumentation) nozzle are discussed. It is recommended that more detailed analysis and experiments are necessary to solve the uncertainties of corium behavior in the lower plenum of the reactor vessel.

KEYWORDS : Severe Accident, In-Vessel Corium Retention, External Reactor Vessel Cooling, Thermal Load, Layer Inversion, Natural Convection, Crust Formation

\section{INTRODUCTION}

The IVR (In-Vessel corium Retention) through the ERVC (External Reactor Vessel Cooling) is known to be an effective means for maintaining reactor vessel integrity during a severe accident in a nuclear power plant $[1,2]$. This measure is adopted in low and medium power reactors, such as the AP600, the AP1000[3, 4], the Loviisa nuclear power plant[5], and the KERENA[6] as a design feature for severe accident mitigation, and in the high-power reactors of the APR (Advanced Power Reactor) 1400 and the $\mathrm{APR}^{+}$(Advanced Power Reactor Plus) as an accident management strategy[7-9]. Many studies have been performed to evaluate the IVR-ERVC [10-13], but more efforts are needed to solve the uncertainties of IVRERVC evaluation.

Success criteria for the IVR-ERVC achievement is determined by a comparison of the thermal load from the corium to the outer reactor vessel with a maximum heat removal rate of $\mathrm{CHF}$ (Critical Heat Flux) on the outer reactor vessel. The $\mathrm{CHF}$ is determined to fix the maximum heat removal rate through the external coolant between the outer reactor vessel and the insulation of the reactor vessel. Many studies regarding the $\mathrm{CHF}$ on the outer reactor vessel, such as ULPU[14-16] and SULTAN[17-18], have been performed. For an application of the IVR-ERVC to a new nuclear power plant, it is necessary to verify water contact to the spherical outer reactor vessel and to determine the $\mathrm{CHF}$.

Corium behavior in the lower plenum of the reactor vessel during a severe accident is also important, because this affects thermal load from the corium to the outer reactor vessel under the IVR-ERVC condition and reactor vessel failure mechanisms for containment analysis. There are many uncertainties on the corium behavior in the lower plenum of the reactor vessel. This paper discusses technical issues of the corium behavior for the evaluation of the IVR-ERVC. The main physics of the corium behavior in the lower plenum is initial corium pool formation, layer inversion between the oxidic and metallic layers in the corium pool, natural convection heat transfer in various geometries, natural convection heat transfer with crust formation, and a corium interaction with spherical lower head vessel including penetrations of the ICI(In Core Instrumentation) nozzle.

\section{MOLTEN POOL FORMATION CHARACTERISTICS IN THE LOWER PLENUM}

When the core materials melt in nuclear power plants, cooling of the melted core material is very important to mitigate in-vessel severe accident progression. If the cooling 
is insufficient in the core region, the melted core material relocates to the lower plenum of the reactor vessel and forms the corium pool with or without a debris bed in conditions with or without water. Fig. 1 shows the typical corium pool formation in the lower plenum of the reactor vessel. In general, a molten corium pool including metallic materials, such as stainless steel and Zircaloy, and oxide materials, such as $\mathrm{UO}_{2}$ and $\mathrm{ZrO}_{2}$, may form at the initial stage. The corium pool may be stratified into two layers,

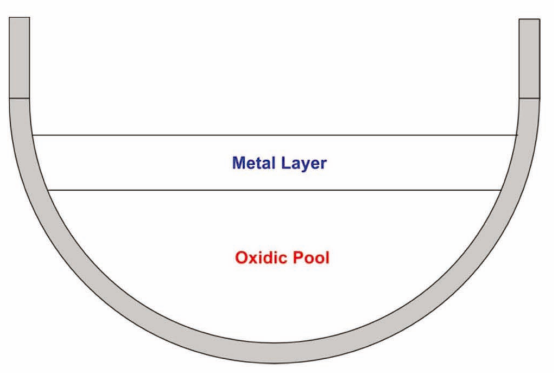

(Typical Two Layer Formation)

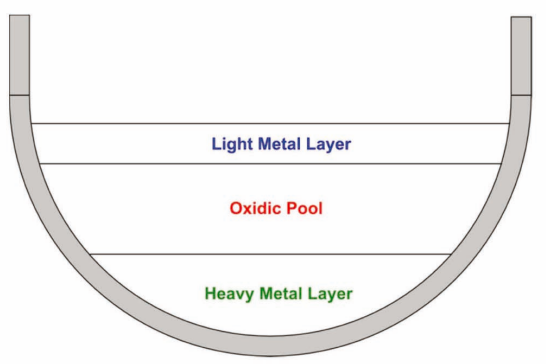

(Three Layer Formation by Layer Inversion)

Fig. 1. Typical Corium Pool Formation in the Lower Plenum of the Reactor Vessel. due to their density differences, an upper metallic layer without a volumetric heat source and a lower oxide layer with a volumetric decay heat source. This two-layer melt pool formation is assumed to be a bounding melt pool configuration for the thermal load analyses under the IVR-ERVC condition.

The experimental results of the OECD MASCA have shown that when a sufficient amount of non-oxidized zirconium $(\mathrm{Zr})$ is available, metallic uranium (U) migrates to the metallic layer [19]. The transfer of species between the $\mathrm{U}, \mathrm{O}, \mathrm{Zr}$ melt and the steel can result in a significant density increase of the metallic phase. The density increase of the metallic phase can lead to inverse corium pool stratification with an additional heavy metal layer below the oxidic pool, which leads to three layer formation as shown in Fig. 1. The presence of the metallic layer at the bottom of the lower head is likely to decrease the thickness of the top metallic layer and consequently to increase the thermal load to the lower head vessel, which is the focusing effect in the top metallic layer.

The density increase of the metallic layer is due to dissolution of uranium into a metallic phase. The thermodynamic calculations are aimed at determining the composition of a $\mathrm{U}-\mathrm{Zr}-\mathrm{Fe}-\mathrm{O}$ mixture at thermodynamic equilibrium for a given temperature. The results of these calculations mainly depend on the $\mathrm{U} / \mathrm{Zr}$ ratio, the $\mathrm{Zr}$ oxidation fraction, the mass of $\mathrm{UO}_{2}$ and the mass of steel [20]. The less $\mathrm{Zr}$ is oxidized, the higher mass of the metal can stratify below the oxidic pool. For a given mass of $\mathrm{UO}_{2}$, when the mass of metallic $\mathrm{Zr}$ increases then it favors the dissolution of $\mathrm{UO}_{2}$ and the transfer of metallic uranium to the metal layer. This leads to a significant increase of the mass of the metal layer and a layer inversion.

Fig. 2 shows the MASCA results on melt pool formation. In case of a low iron to corium ratio and low degree of corium oxidation, a layer inversion occurred. The molten

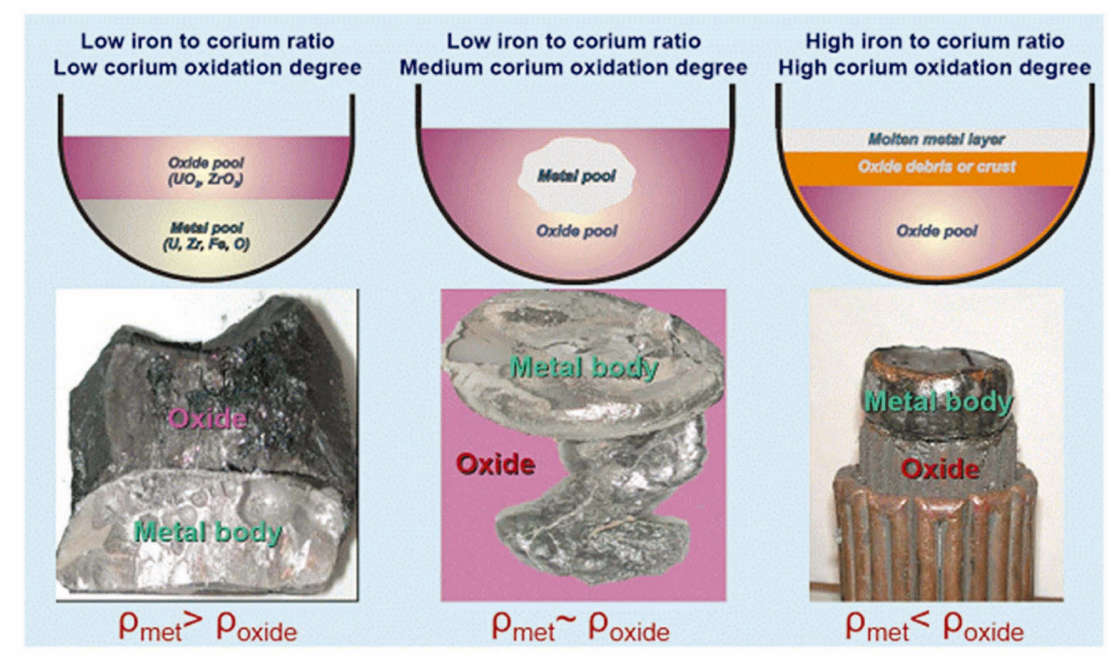

Fig. 2. MASCA Results on Melt Pool Formation in the Lower Plenum. 
steel extracted some metallic uranium and zirconium from sub-oxidized corium. However, layer inversion did not occur in the high iron to corium ratio and high degree of corium oxidation. The following is analysis results on two or three layer melt pool configurations in the lower plenum of the APR(Advanced Power Reactor)1400 reactor vessel.

\section{Melt Pool Configuration in the APR1400}

The initial melt pool conditions, such as melt mass, melt pool temperature and so on, were determined by using the SCDAP/RELAP5 computer code[21] for two severe accident sequences of the APR1400 at KAERI(Korea Atomic Energy Research Institute)[22]. In this analysis, TLFW(Total Loss of Feed Water) and SBLOCA(Small Break Loss of Coolant Accident) without SI(Safety Injection) were selected as the main severe accident sequences, which come from the level 1 PSA(Probabilistic Safety Assessment) results for the APR1400.

Table 1 summarizes the final melt pool states in the lower plenum of the APR 1400 for two major severe accident sequences. The SCDAP/RELAP5 results such as the mass and the temperature of melt compositions were used as an input for thermo-dynamic calculations. The mass of stainless steel and $\mathrm{B}_{4} \mathrm{C}$ control rod were assumed to be 50 tons and 1.4 tons, respectively. $\mathrm{Zr}$ oxidation rate $(\mathrm{Cn})$ is defined as the oxidation rate of the corium by the molar ratio, $\mathrm{ZrO}_{2} /\left(\mathrm{Zr}+\mathrm{ZrO}_{2}\right)$, and the $\mathrm{U} / \mathrm{Zr}$ ratio is a molar ratio.

The thermodynamic analyses were performed using the GEMINI computer code[23]. For a given temperature, the compositions of a $\mathrm{U}-\mathrm{Zr}-\mathrm{Fe}-\mathrm{O}$ mixture were determined under the thermodynamic equilibrium conditions. Combined with the GEMINI code calculations and the peer review on the RASPLAV/MASCA experimental results, the final melt pool configurations were determined for the two major accident scenarios of the APR1400. The GEMINI code calculates complex multiphase multi-component chemical equilibriums by minimizing the total Gibbs energy of the system under either constant pressure or volume conditions.

Table 2 shows the GEMINI results for the mass distribution of the individual melt components. In this study, through the GEMINI calculation, the mass of the individual melt component which was involved in the metallic phase and oxidic phase was determined. Layer inversion phenomena were evaluated using the GEMINI results. For the quantitative evaluation on the layer inversion phenomena, the density variation of oxidic and metallic phases under the thermodynamic equilibrium should be determined. In addition, the systematic effects of the U/Zr ratio, the $\mathrm{Zr}$ oxidation fraction, the mass of $\mathrm{UO}_{2}$ and steel should be considered.

Table 1. SCDAP/RELAP5 Results of Final Corium Configuration in the Lower Plenum of the APR1400 Reactor Vessel.

\begin{tabular}{c|c|c}
\hline & TLFW & SBLOCA \\
\hline Corium Mass (ton) & 194.5 & 171.1 \\
\hline $\mathrm{UO}_{2}$ Mass (ton) & 113.2 & 99.6 \\
\hline $\mathrm{ZrO}_{2}$ Mass (ton) & 18.2 & 13.4 \\
\hline Zr Mass (ton) & 11.7 & 6.7 \\
\hline Stainless Steel Mass (ton) & 50.0 & 50.0 \\
\hline $\mathrm{B}_{4}$ C mass (ton) & 1.4 & 1.4 \\
\hline Corium Temperature (K) & 2,900 & 3,083 \\
\hline Zirconium Oxidation Fraction (Cn) & 54.0 & 60.0 \\
\hline U/Zr Ratio & 1.5 & 2.0 \\
\hline
\end{tabular}

Table 2. GEMINI Results of the Corium Composition in the Lower Plenum of the APR1400 Reactor Vessel (unit: ton).

\begin{tabular}{c|c|c|c|c}
\hline \multirow{2}{*}{} & \multicolumn{2}{|c|}{ TLFW } & \multicolumn{2}{c}{ SBLOCA } \\
\cline { 2 - 5 } & Metallic Layer & Oxidic Layer & Metallic Layer & 0.12 \\
\hline $\mathrm{B}$ & 1.01 & 0.09 & 0.73 & 0.00 \\
\hline $\mathrm{C}$ & 0.30 & 0.00 & 0.01 & 0.10 \\
\hline $\mathrm{Cr}$ & 8.76 & 0.24 & 2.33 & 0.15 \\
\hline $\mathrm{Fe}$ & 35.88 & 0.12 & 26.35 & 0.09 \\
\hline $\mathrm{Ni}$ & 3.92 & 0.08 & 3.16 & 14.10 \\
\hline $\mathrm{O}$ & 0.30 & 17.84 & 0.23 & 73.51 \\
\hline $\mathrm{U}$ & 14.65 & 85.14 & 3.96 & 12.61 \\
\hline $\mathrm{Zr}$ & 6.05 & 19.12 & & \\
\hline
\end{tabular}


It could be found that the less zirconium is oxidized, the higher mass of metal can stratify below the oxidic pool. In order to evaluate the melt layer inversion for the SBLOCA without the SI and TLFW sequences of the APR1400, a density evaluation graph for oxidic and metallic layers was developed considering the exact initial melt pool conditions such as the $\mathrm{U} / \mathrm{Zr}$ ratio, the $\mathrm{Zr}$ oxidation fraction, and the mass of $\mathrm{UO}_{2}$. For the SBLOCA without the SI and TLFW sequences in the APR1400, the U/Zr ratio, the $\mathrm{Zr}$ oxidation fraction, and the mass of $\mathrm{UO}_{2}$ were determined by using the SCDAP/RELAP5 results.

Using the density evaluation graph, the mass of the metallic layer which is heavier than the oxidic phase can be calculated[24]. In addition to an iron mass relocated below the oxidic pool, the whole metallic uranium and the part of metallic zirconium can stratify below the oxidic pool. Metallic zirconium can be distributed between the heavy metallic layer and the light metallic layer. Since the estimation of the metallic zirconium partitioning between the heavy and light metallic layer is difficult, it calculates by assuming that the mass fraction of uranium is fixed at
0.4 among the total mass of the heavy metallic phase below the oxidic pool [24]. The total mass of the heavy metallic layer below the oxidic pool can be obtained by summing the iron, uranium, and zirconium in each accident sequence of the APR1400. Figs. 3 and 4 show the melt pool configuration of the SBLOCA without the SI and TLFW sequences of the APR1400. Melt pool configurations were different in the two severe accident sequences of the APR1400. Since the U/Zr ratio and the initial melt pool temperature were relatively higher in case of the SBLOCA without the SI, the layer inversion did not occur as shown in Fig. 3. However, the layer inversion occurred in the TLFW sequence as shown in Fig. 4.

Based on the thermodynamic analysis results, a series of tests, named COSMOS (Corium configuration of the molten State in the Most Severe Accidents), are in progress at KAERI. Since the melt pool configurations were different in the SBLOCA without the SI and TLOFW sequences of the APR1400, a series of tests will be performed for the initial melt pool conditions of two severe accident sequences of the APR1400. Fig. 5 shows the

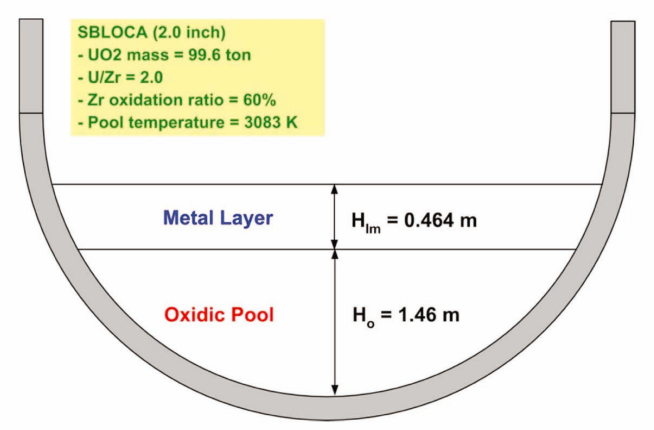

Fig. 3. Melt Pool Configuration for the SBLOCA in the APR 1400.

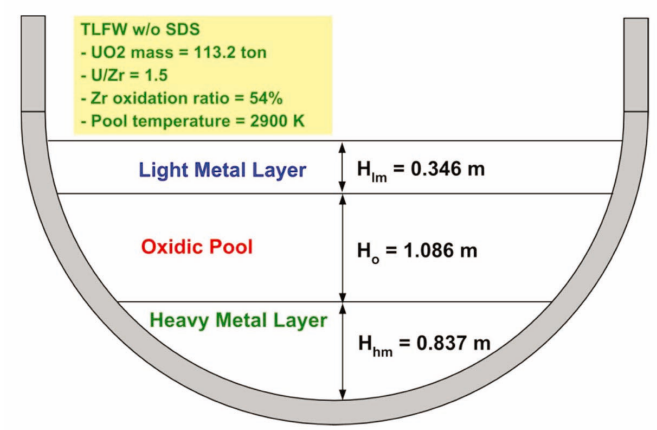

Fig. 4. Melt Pool Configuration for the TLFW in the APR1400.

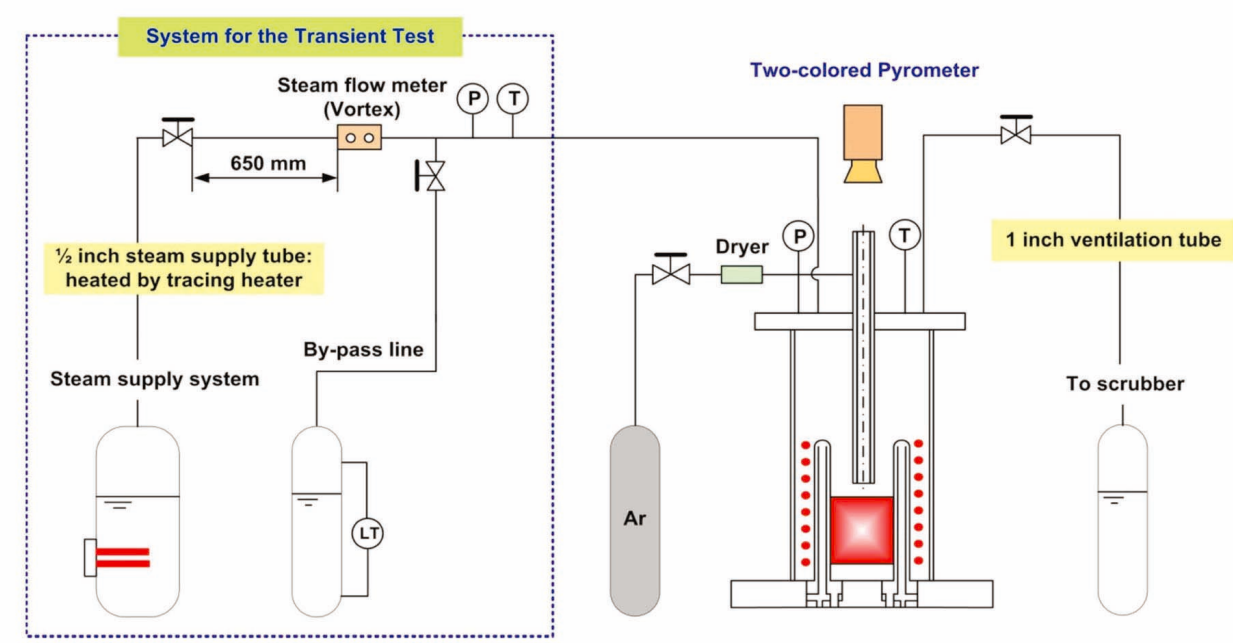

Fig. 5. Schematic Diagram of the COSMOS Test Facility. 
schematic diagram of the COSMOS test facility. A photograph of the test section is shown in Fig. 6. An induction heating method using a cold crucible was implemented for melting of the prototypic $\mathrm{UO}_{2}-\mathrm{ZrO}_{2}-\mathrm{Zr}$ Fe mixture in the COSMOS test. The maximum electric power and frequency of the generator were $100 \mathrm{~kW}$ and $120 \mathrm{kHz}$, respectively. The inner diameter and the height of the crucible were $9.45 \mathrm{~cm}$ and $25 \mathrm{~cm}$, respectively.

As a preliminary test in the framework of the COSMOS program, the COSMOS-001 was performed with an aim of experimental investigation on the detailed phenomena of a layer inversion for the melt configuration corresponding to the TLFW sequence in the APR1400. A series of the COSMOS tests will be performed not only to provide physical insight into the layer inversion phenomena of the heavy metallic layer but also to produce metallurgical inspection test data to validate the thermodynamic analysis methodology using the GEMINI code.

\section{Transient Behavior of the Melt Pool}

The following transient behavior of the melt pool in the lower plenum affects the thermal load to the outer reactor vessel and plays a key role in determining the integrity of the reactor vessel.

- Pool transient behaviour : Isothermal, surface oxidation, oxidation kinetics with crust formation on top, and links to inversion kinetics

- Kinetics of species transfer when the crust is formed between molten oxide and metal layers

The accident conditions have a significant impact on the success of the IVR-ERVC as they modify the main

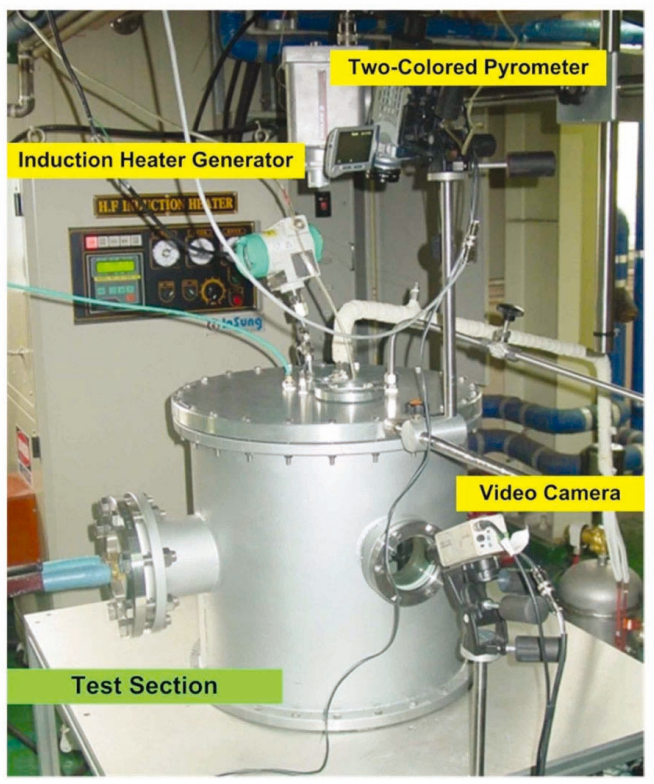

Fig. 6. Photograph of the COSMOS Test Section. governing parameters such as the steam flow rate, progressive steel addition and gradual temperature increase. Moreover, transient evolutions induce non-uniformities, such as temperature gradients or local variations of composition, which result in conditions far from the "overall equilibrium conditions", thus leading to uncertainties in the predictions. Therefore, there are still uncertainties on the application of existing results including MASCA to models for reactor cases. These include scaling effects, but also the influence of transient processes occurring simultaneously: oxidation, dissolution, melt progression and/or stratification. In order to predict the heat flux through the reactor vessel head, it is necessary to establish an overall view of the possible transient evolutions of corium and to determine a steady-state corium configuration after debris melts. There is a major interest to study interactions involving transient situations. It would be of interest to study the evolution of the system starting with debris bed, exposure at high temperature for a relatively long time, transformation into a corium pool and finally refreezing of the melt.

\section{HEAT TRANSFER MECHANISM IN THE MOLTEN POOL}

When the corium pool of two or three layers forms in the lower plenum of the reactor vessel, many types of natural convection heat transfer are generated. Fig. 7 shows the natural convection heat transfer in the upper metallic layer of the two layer or three layer corium pools, which is the bottom heating from the oxidic pool, top cooling of the upper coolant, and the side wall heat flux of the focusing effect. If the side wall is insulated, this is Rayleigh-Benard natural convection heat transfer. When natural convection flow develops, the flow and temperatures are complex functions of the governing parameters; the Rayleigh number(Ra), the Prandtl number(Pr), and the aspect ratio(AR), which are defined in Nomenclature. Many studies have been performed for the RayleighBenard problem. This kind of natural convection study is summarized in Reference [1]. However, analytical and experimental results are limited in the heat transfer style of Fig 7 including the side wall heat transfer. Despite the large amount of researches in this heat transfer field, there is a lack of information on low Prandtl number fluids, especially at high Rayleigh numbers, and furthermore, the aspect ratio effect is not fully understood. More analysis and experiment are necessary to solve the focusing effect including the multi dimensional heat conduction through the lower head vessel.

Fig. 8 shows the natural convection in the lower oxidic layer of the two layer corium pool. This is the natural convection heat transfer problem with volumetric decay heat source. Many studies on the natural convection heat transfer with the volumetric heat source have been 


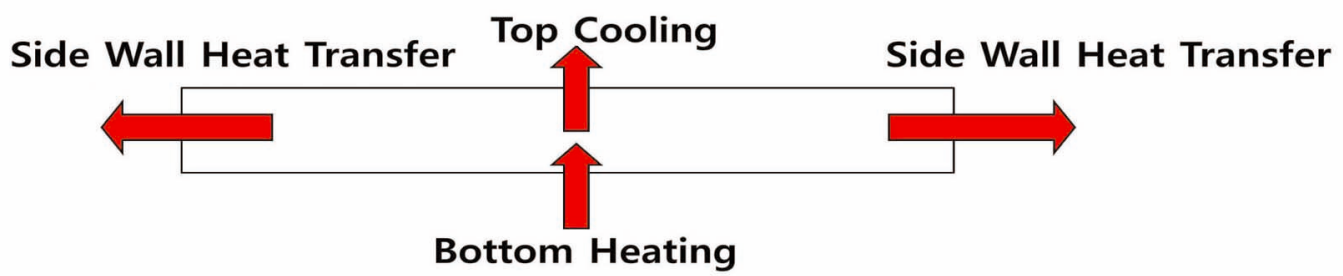

Fig. 7. Heat Transfer in the Upper Metallic Layer of the Two Layer or Three Layer Corium Pools.

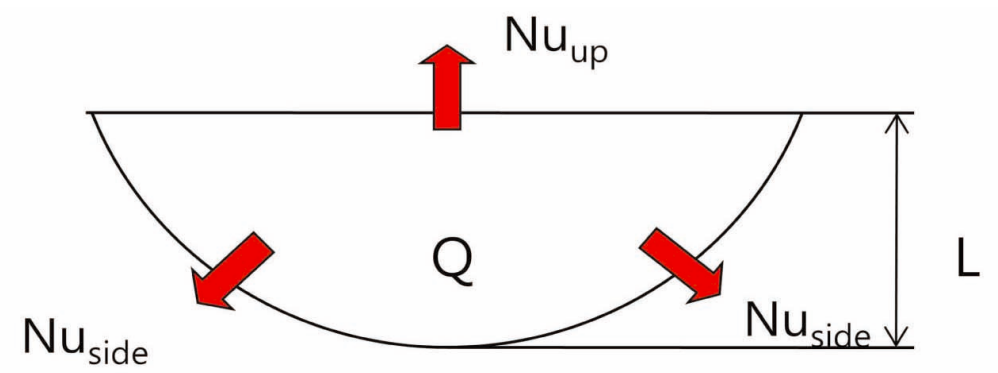

Fig. 8. Heat Transfer in the Lower Oxidic Layer of the Two Layer Corium Pool.

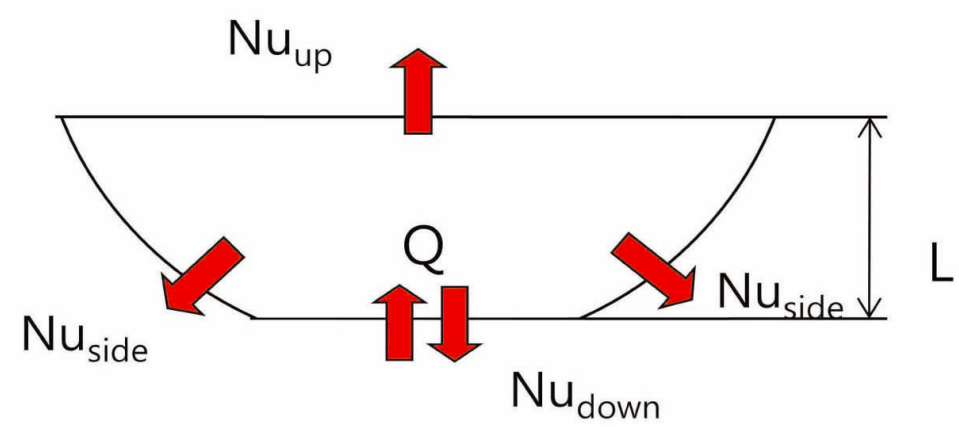

Fig. 9. Heat Transfer in the Middle Oxidic Layer of the Three Layer Corium Pool.

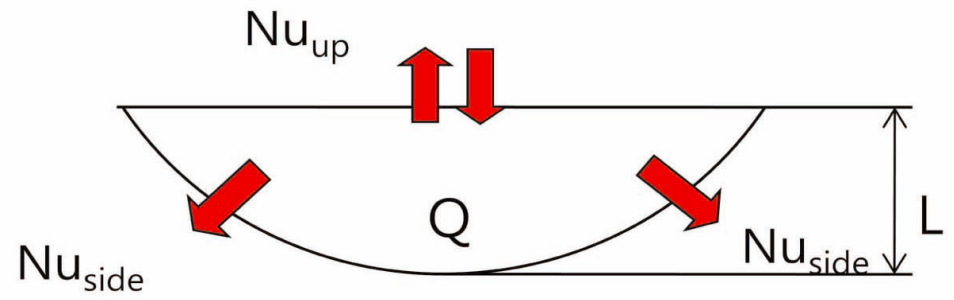

Fig. 10. Heat Transfer in the Lower Metallic Layer of the Three Layer Corium Pool.

performed, and are summarized in Reference [1]. However, analytical and experimental results are limited in the case of high Rayleigh number and low Prandtl number. The corium pool in the lower plenum may reach the range of Rayleigh number $10^{15} \sim 10^{16}$ for the oxide pool and $10^{9} \sim 10^{10}$ for the metallic layer.

Fig. 9 shows the natural convection in the middle oxidic layer of the three layer corium pool. This is the natural convection heat transfer problem with volumetric decay heat source. Fig. 10 shows the natural convection in the bottom metallic layer of the three layer corium pool. This is the natural convection heat transfer problem with a small volumetric decay heat source. Since there is no study on these two special geometries, detailed analysis and experiment are necessary to solve the natural convection heat transfer. 


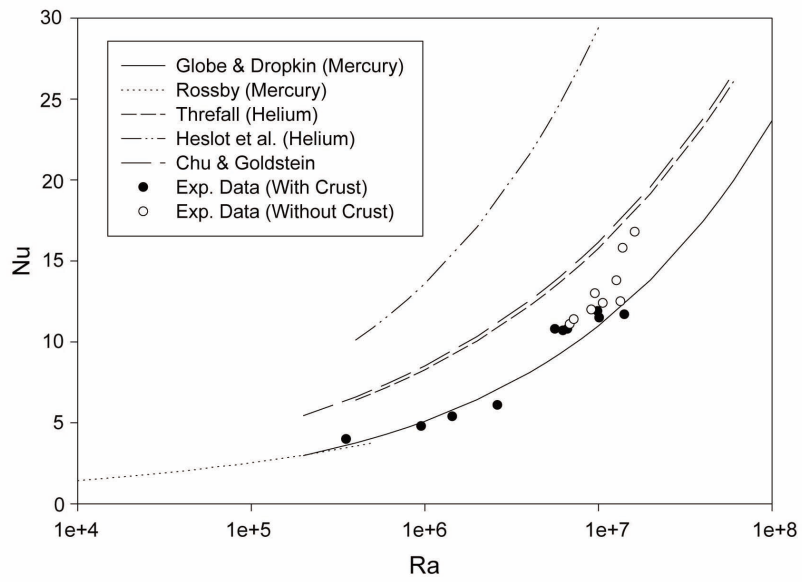

Fig. 11. Comparison of the KAERI's Experimental Results with and without Crust Formation in the High Aspect Ratio Case of Natural Convection Cooling, with other Correlations.

\section{Natural Convection with Crust Formation}

If heat transfer from the corium to the surrounding is effective, a layer of crust in the corium pool may be formed by solidification of the molten metallic materials. As the crust formation affects corium pool coolability, it should be understood precisely. Few studies on crust formation and its effect on natural convection heat transfer in the corium pool have been performed[25, 26]. An experiment on a natural convection heat transfer with solidified crust formation in the molten metal pool was performed by KAERI to investigate a crust effect on heat transfer characteristics from the molten metal pool to the coolant in both low and high aspect ratio cases. Two types of steady state tests, natural and forced convection cooling cases, were performed to examine the effect of cooling conditions on the natural convection heat transfer with and without crust formation in low and high aspect ratio cases[27, 28].

The natural convection flow in the molten metal pool region substantially affects the crust formation, which was evaluated quantitatively. The KAERI's results on the relationship between the Nusselt number and Rayleigh number in the molten metal pool region was compared to other correlations, which were developed through experiments on the Rayleigh-Benard problem concerning natural convection in a horizontal fluid layer heated from below and cooled from above. Experimental results have been reported by Globe and Dropkin[29], Rossby[30], Threlfall[31], Heslot et al.[32], and Chu and Goldstein[33], among others. The mercury data of Globe and Dropkin and of Rossby represent the only available heat transfer data for liquid metal, but these studies were performed without crust formation.

Fig. 11 shows a comparison of the KAERI's

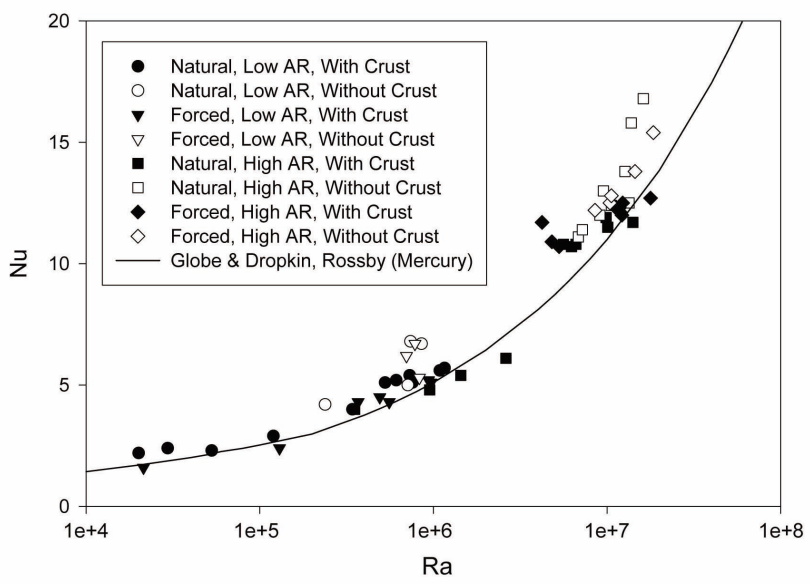

Fig. 12. Comparison of the Low Aspect Ratio Case with the High Aspect Ratio Case.

experimental results with and without crust formation in the high aspect ratio with existing correlations. The Nusselt numbers of Globe and Dropkin's and of Rossby's correlations are lower than those of any others, because they used a molten metal having low Prandtl number as a working fluid. As seen from the Figure, the experimental results match better with the results of Globe and Dropkin's correlation than any others. Nevertheless, the experimental results with crust formation are approximately $8 \%$ greater than the results of Globe and Dropkin's correlation. However, the experimental results without crust formation are approximately $15 \%$ greater than the results of Globe and Dropkin's. It can be confirmed from the comparison that the heat transfer rate of cases without crust formation is greater than that of cases with crust formation because the crust acts as a conducting thermal barrier.

Fig. 12 shows a comparison of the KAERI's experimental results in low and high aspect ratio cases with Globe and Dropkin's and Rossby's correlations. The experimental results with and without crust formation in the low aspect ratio are approximately $20 \%$ and $30 \%$ higher than the results of Globe and Dropkin's and of Rossby's, respectively. From a comparison of the low aspect ratio case with the high aspect ratio case, the natural convection heat transfer rate of the low aspect ratio case is higher than that of the high aspect ratio case. Therefore, natural convection heat transfer in a low aspect ratio case is more substantial than that in a high aspect ratio case at the same Rayleigh number and Prandtl number conditions due to the wall effects.

In spite of the lower Prandtl number $(\mathrm{Pr}=0.017)$ and of the crust serving as a conducting thermal barrier, the KAERI's experimental results on natural convection heat transfer rate with crust formation are a little higher than those of the Globe and Dropkin's correlation $(\operatorname{Pr}=0.022)$. An increase in the crust thickness leads to a decrease in 
the Nusselt number, due to a rapid decrease in the Rayleigh number. The increase in the crust thickness, however, leads to a decrease in the aspect ratio. This decrease in the aspect ratio leads to increase in the Nusselt number, due to the wall effects.

An experiment was also performed by KAERI to investigate the natural convection heat transfer with crust formation of the molten metal pool concurrent with forced convective boiling of the overlying coolant[34, 35]. In the test, the temperature distribution and crust layer thickness in the metal layer were appreciably affected by the heated bottom surface temperature of the test section, but not much by the coolant injection rate[27]. In this experiment, the heat transfer was accompanied by solidification of the molten metal pool with boiling coolant. The experimental results on the heat transfer of the molten pool with coolant boiling were apparently higher than those without coolant boiling. This is probably because this experiment was performed in concurrence with solidification in the molten metal pool and the rapid boiling of the coolant. Further study is necessary to investigate the effect of the boiling coolant on the natural convection heat transfer with crust formation in the high temperature and high Rayleigh number region.

\section{CORIUM INTERACTION WITH LOWER HEAD VESSEL}

When the melted core material relocates to the lower plenum of the reactor vessel during a severe accident, the lower head vessel including penetrations of the ICI nozzles may fail from melt attack[36]. In the TMI-2 accident, the hot spot in the lower head vessel was generated by corium attack in spite of water existence in the lower plenum of the reactor vessel[37].

The METCOR experimental study of physicochemical phenomena occurring at the interaction between a molten corium pool and reactor vessel steel was performed[38, 39] in Russia. The METCOR reported the systematized data on the vessel steel corrosion in the conditions of the IVRERVC for the steady temperature and oxygen potential and the horizontal position of the interaction interface. A comprehensive analysis of the reactor failure requires the data on the vessel corrosion at its interaction with molten corium in realistic conditions, primarily at higher temperatures of steel, different positions of the interaction interface, and changed oxygen potential of the system. The METCOR results showed the influence of physicochemical phenomena on the depth and kinetics of reactor vessel ablation under the IVR-ERVC condition. In spite of the METCOR experiment, more studies are necessary for corium interaction with steel vessel during the melt oxidation transients.

The heat flux distribution in the corium pool is very important to evaluate the IVR-ERVC. Since the lower head vessel is a conductive material, the heat flux distribution in the corium pool may be changed on the outer reactor vessel wall. The detailed multi-dimensional heat conduction through the spherical lower head vessel should be analyzed to evaluate a success criterion of the IVR-ERVC.

\section{Lower Head Penetration Integrity}

During melt relocation to the lower plenum, the lower head vessel including the ICI nozzle and the thimble tube may fail from corium melt attack. The attack of the melted core material to the lower head penetrations of the reactor vessel may result in the melt entering a penetration channel and heating up the penetration tube, thus causing blockage of the penetrations and potentially a penetration rupture. The melted core material attack and sustained heating from accumulated core material may lead to ICI nozzle weld failure and subsequent ICI nozzle ejection to the reactor cavity, which means reactor vessel failure. No weld failures were observed in the TMI- 2 accident and consequently, no penetrations were ejected from the lower head. However, the molten core material did enter the instrumentation tube central chamber and penetrate significant distances outside the reactor vessel. The water inside the annulus between the ICI nozzle and the thimble tube was important for the integrity maintenance of the reactor vessel penetrations, which did not result in any failure of penetration in the TMI-2 accident[37].

In order to estimate the effects of the water inside the annulus and the ERVC for the maintenance of reactor vessel integrity, an experiment was conducted by KAERI under an elevated pressure of 1.0 $\mathrm{MPa}$ using alumina $\left(\mathrm{Al}_{2} \mathrm{O}_{3}\right)$ melt as a corium simulant in the APR1400[40, 41]. A series of tests with various external vessel cooling conditions were performed to estimate the effects of invessel pressure, melt mass, and melt flow due to vessel geometry change from flat plate to a $20^{\circ}$ inclination for the maintenance of penetration integrity of the reactor vessel. The possibility of weld failure and melt ingression into the penetration was estimated using the test results of the temperature history and post-test examinations.

Table 3 shows the lower head penetration geometry as a plant type. The penetration geometry varies by plant type. The thickness of the reactor vessel and the depth of the welding between the ICI nozzle and the reactor vessel in the APR1400 are $163 \mathrm{~mm}$ and $43 \mathrm{~mm}$, respectively. The weld material is ERNiCrFe-7. Table 4 shows the comparison of the various experiments on penetration failure. The FAI(Fauske Associates Institute) in the USA performed the experiments to evaluate the penetration integrity using thermite melt as a stimulant under the ERVC condition[42]. The main focus of FAI's experiment was the penetration distance of the debris through the inner part of the thimble tube. Their test results showed no penetration failure. The CORVIS test [43] at the Paul 
Table 3. Lower Head Penetration Geometry as a Plant Type.

\begin{tabular}{c|c|c|c|c}
\hline & TMI- & W-PWR(Typical) & OPR1000 & APR1400 \\
\hline Inner Diameter of the Lower Reactor Vessel (m) & 4.44 & 4.20 & 4.22 & 0.1524 \\
\hline Thickness of the Lower Reactor Vessel (m) & 0.127 & 0.14 & 45 & 0.165 \\
\hline Total Number of the ICI Nozzles & 52 & 58 & 61 \\
\hline Material and Outer Diameter of the ICI Nozzle (m) & $\begin{array}{c}\text { Inconel 600, } \\
0.0508\end{array}$ & $\begin{array}{c}\text { Inconel } 600, \\
0.0274\end{array}$ & $\begin{array}{c}\text { Inconel 690, } \\
0.0762\end{array}$ & $\begin{array}{c}\text { Inconel 690, } \\
0.0762\end{array}$ \\
\hline Thickness of the ICI Nozzle (m) & 0.01746 & 0.0064 & 0.0286 & 0.0286 \\
\hline Thickness of the Water Filled Annulus (m) & 0.00423 & 0.0023 & 0.00381 & 0.00381 \\
\hline Material and Outer Diameter of the Thimble Tube (m) & Inconel, 0.00742 & St. Steel, 0.008 & St. Steel, 0.01143 & St. Steel, 0.01143 \\
\hline Thickness of the Thimble Tube (m) & 0.000535 & 0.0012 & 0.001245 & 0.001245 \\
\hline
\end{tabular}

Table 4. Experiments on Penetration Tube Failure Mechanism.

\begin{tabular}{c|c|c|c|c}
\hline & KAERI & FAI & CORVIS & LHF \\
\hline Place & KAERI, Korea & FAI, U.S.A. & PSI, Switzland & SNL, U.S.A. \\
\hline Reactor Type & APR1400 & $\underline{\text { W PWR, GE PWR, BWR }}$ & BWR, PWR & PWR \\
\hline Total Test Numbers & 6 & 10 & 3 & $2(\mathrm{LHF}-4, \mathrm{LHF}-5)$ \\
\hline Simulant and Mass $(\mathrm{kg})$ & $\mathrm{Al}_{2} \mathrm{O}_{3} 40, \mathrm{Al}_{2} \mathrm{O}_{3} 60$ & $\mathrm{Al}_{2} \mathrm{O}_{3} 20, \mathrm{Al}_{2} \mathrm{O}_{3} 40$ & $\mathrm{Al}_{2} \mathrm{O}_{3}+\mathrm{Fe} 800, \mathrm{Al}_{2} \mathrm{O}_{3} 400$ & Electrical Heater \\
\hline In-Vessel Pressure $(\mathrm{MPa})$ & $1.0-1.5$ & $0-1.7$ & 0.1 & 10.0 \\
\hline Condition of OuterVessel & $\begin{array}{c}\text { With \& Without External } \\
\text { Cooling }\end{array}$ & $\begin{array}{c}\text { With External Vessel } \\
\text { Cooling }\end{array}$ & $\begin{array}{c}\text { Without External Vessel } \\
\text { Cooling }\end{array}$ & $\begin{array}{c}\text { Without External Vessel } \\
\text { Cooling }\end{array}$ \\
\hline $\begin{array}{c}\text { Main Focus of the } \\
\text { Experiment }\end{array}$ & $\begin{array}{c}\text { Tube Ejection by Weld } \\
\text { Ablation \& Penetration } \\
\text { Distance }\end{array}$ & $\begin{array}{c}\text { Penetration Distance of } \\
\text { Debris }\end{array}$ & $\begin{array}{c}\text { Failure Mechanism of } \\
\text { Penetration }\end{array}$ & $\begin{array}{c}\text { Failure Mechanism of } \\
\text { Penetration }\end{array}$ \\
\hline
\end{tabular}

Scherrer Institute in Switzerland and LHF(Lower Head Failure)-4, 5 tests [44] at the SNL in the USA were performed to estimate the failure mechanism of the penetration using thermite melt as a simulant and an electrical heater, respectively, without the ERVC condition. The CORVIS test results showed failure of BWR(Boiling Water Reactor) drain line. The LHF 4 and 5 test results showed the penetration weld failure.

The main focus of the KAERI's experiment was to evaluate the possibility of tube ejection by weld ablation, and penetration failure by melt ejection into the annulus between the ICI nozzle and the thimble tube. Fig. 13 shows KAERI's experimental results on the damage states of the test sections. The inner surface of the lower head vessel and welding material were ablated to thicknesses of 10 $\mathrm{mm}$ and $32 \mathrm{~mm}$, respectively. The penetration distance was $72 \mathrm{~mm}$ in the test. An increase of system pressure led to a small increase in penetration damage. The melt mass increase and the vessel geometry change to a flat plate with a $20^{\circ}$ incline led to a large increase in penetration damage. An increase in system pressure from 1.0 MPa to 1.5 MPa was not effective for penetration damage, but an increase in corium mass from $40 \mathrm{~kg}$ to $60 \mathrm{~kg}$ and the vessel geometry change to a flat plate with a $20^{\circ}$ incline were effective on the penetration damage. The average heat flux through the vessel was $0.2-0.3 \mathrm{MW} / \mathrm{m}^{2}$, which is a lower value compared with the IVR-ERVC condition of the APR1400. More studies are necessary to evaluate reactor vessel penetration integrity in conditions with an increased heat flux from the molten pool to the reactor vessel, because the heat flux depends on severe accident sequences. 


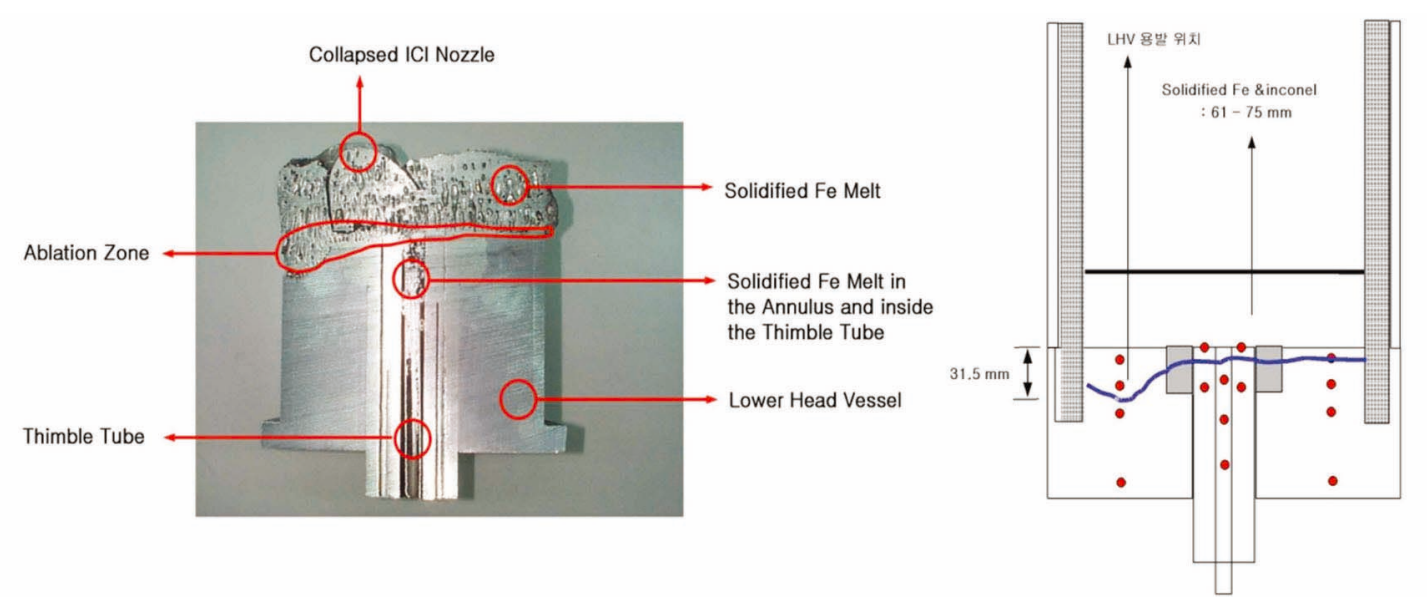

Fig. 13. KAERI's Experimental Results on the Damage State of the ICI Nozzle.

\section{CONCLUDING REMARKS}

This paper discusses the state of the art and technical issues on the corium behavior in the lower plenum of the reactor vessel, such as initial corium pool formation characteristics and its transient behavior, natural convection heat transfer in various geometries, natural convection heat transfer with phase change of melting and solidification, corium interaction with lower head vessel including penetrations of the ICI nozzle. The density increase of the metallic phase can lead to inverse corium pool stratification with an additional heavy metal layer below the oxidic pool, which leads to three layer formation. The accident conditions have a significant impact on the success of the IVR-ERVC as they modify the main governing parameters, such as the steam flow rate, the progressive steel addition, and the gradual temperature increase. Despite the large amount of research dedicated to natural convection heat transfer, there is a lack of information on low Prandtl number fluids, especially at high Rayleigh numbers, and furthermore, the aspect ratio effect is not fully understood, in particular, natural convection with crust formation. Since the lower head vessel is a conductive material, the heat flux distribution in the corium pool may be changed on the outer reactor vessel wall under the IVR-ERVC condition.

More detailed analysis and experiments are necessary to solve uncertainties of the corium behavior in the lower plenum under the IVR-ERVC condition, which are as follows;

- Experiments and analysis on the initial melt pool formation and its transient behavior

- Correlation development on natural convection heat transfer for the various corium pool geometries in the high Rayleigh number and low Prandtl number conditions by using detailed analysis and its verification experiments
- Model development on the natural convection heat transfer with phase change of melting and solidification, and its verification experiments

- Analysis and experiments to solve the focusing effect including the multi dimensional heat conduction through the lower head vessel

- Model development and experiment on corium interaction with the lower head vessel including penetrations of the ICI nozzle

\section{NOMENCLATURE}

$A R=$ aspect ratio in the molten pool $(=\mathrm{L} / \mathrm{X})$

$c \quad=$ specific heat, $\mathrm{J} /(\mathrm{kg} . \mathrm{K})$

$g \quad=$ acceleration due to gravity, $\mathrm{m} / \mathrm{s}^{2}$

$h=$ heat transfer coefficient, $\mathrm{W} /\left(\mathrm{m}^{2} \mathrm{~K}\right)$

$k=$ thermal conductivity, $\mathrm{W} /(\mathrm{mK})$

$L \quad=$ height of the pool layer, $\mathrm{m}$

$N u=$ average Nusselt number $(=\mathrm{hL} / \mathrm{k})$

$P r=$ Prandtl number $(=v / \alpha)$

$Q=$ Volumetric decay heat source, $\mathrm{W} / \mathrm{m}^{3}$

$R a=$ Rayleigh number $\left(=\mathrm{g} \beta \Delta \mathrm{TL}^{3} /(\alpha v)\right)$, Bottom heating and top cooling case

$R a=$ Rayleigh number $\left(=\mathrm{g} \beta \mathrm{QL}^{5} /(\alpha v k)\right)$, Internal heat generation case

$T_{b} \quad=$ bottom surface temperature in the test section, $\mathrm{K}$

$T_{t} \quad=$ top surface temperature in the test section, $\mathrm{K}$

$X \quad$ = width of the test section, $\mathrm{m}$

\section{Greek}

$\alpha=$ thermal diffusivity $(=\mathrm{k} /(\rho . \mathrm{c})), \mathrm{m}^{2} / \mathrm{s}$

$\beta=$ coefficient of volume expansion, $1 / \mathrm{K}$

$\Delta T=T_{b}-T_{t}$, temperature difference between the top and bottom surfaces in the metal pool, $\mathrm{K}$

$v \quad=$ kinematic viscosity, $\mathrm{m}^{2} / \mathrm{s}$

$\rho \quad=$ density, $\mathrm{kg} / \mathrm{m}^{3}$ 


\section{ACKNOWLEDGMENTS}

This study has been carried out under the Nuclear R\&D Program by the Korean Ministry of Education, Science and Technology.

\section{REFERENCES}

[1] J. L. Rempe, K. Y. Suh, F. B. Cheung, S. B. Kim, "InVessel Retention of Molten Corium: Lesson Learned and Outstanding issues," Nuclear Technology. 161(2008).

[2] T. G. Theofanous, C. Liu, S. Addition, S. Angelini, O. Kymalainen, and T. Salimassi, "In-Vessel Coolability and Retention of a Core Melt," Nuclear Engineering \& Design, 169(1997).

[3] H. Esmaili, M. Khatib-Rahbar, "Analysis of In-Vessel Retention and Ex-Vessel Fuel Coolant Interaction," NUREG/CR-6849, ERI/NRC 04-201 (2004).

[4] T. G. Theofanous, C. Liu, S. Addition, S. Angelini, O. Kymalainen, and T. Salmassi, "In-Vessel Coolability and Retention of a Core Melt," DOE/ID-10460, Vol. 1\&2(1995).

[5 ] O. Kymalainean, H. Tuomisto, T. G. Theofanous, "InVessel Retention of Corium at the Loviisa Plant", Nuclear Engineering \& Design, 169, 109-130 (1997).

[6] M. Fisher, P. Levi, G. Langrock, "The Impact of Thermal Chemical Phenomena on the Heat Fluxes into the RPV during In-Vessel Melt Retention," ICAPP2011, Nice, France(2011).

[ 7 ] J. W. Park, D. W. Jeong, "An Investigation of Thermal Margin for External Reactor Vessel Cooling (ERVC) in Large Advanced Light Water Reactors (ALWR)", Proceedings of the KNS, Kwangju, Korea(1997).

[8] R. J. Park, K. S. Ha, S. B. Kim, H. D. Kim, “Two-Phase Natural Circulation Flow of Air and Water in a Reactor Cavity Model under External Reactor Vessel Cooling during a Severe Accident", Nuclear Engineering and Design, 236, 2424-2430 (2006).

[9] J W. Park et al., "Design for the In-Vessel Core Melt Retention and the Overall Severe Accident Strategy of the APR1400,' ICAPP '05, Seoul, Korea(2005).

[10] R. E. Henry, H. K. Fauske, "External Cooling of a Reactor Vessel under Severe Accident Conditions", Nuclear Engineering \& Design, 139, 31-43 (1993).

[11] S. H. Yang, W. P. Baek, S. H. Chang, "An Experimental Study of Pool-Boiling CHF on Downward Facing Plates", J. of KNS, 26, 493-501 (1994).

[12] T. Y. Chu, "Ex-vessel Boiling Experiments; Laboratoryand Reactor-scale Testing of the Flooded Cavity Concept for In-Vessel Core Retention Part II: Reactor-scale Boiling Experiments of the Flooded Cavity Concept for In-Vessel Core Retention", Nuclear Engineering \& Design, 169, 8999 (1997).

[13] H. Schmidt, "Large Scale Verification of External RPV Cooling in Case of Severe Accident", ICAPP'04, Pittsburgh, PA, USA, June 13-17 (2004).

[14] T.G. Theofanous and S. Syri, "The Coolability Limits of a Reactor Pressure Vessel Lower Head," Nuclear Engineering and Design, 169, 59-76(1997).

[15] J. H. Scobel, T. G. Theofanous, and L. E. Conway, "InVessel Retention of Molten Core Debris in the Wastinghouse AP1000 Advanced Passive PWR," ICAPP'02, Hollywood, Florida, USA,(2002).
[16] T. N. Dinh, J. P. Tu, and T. G. Theofanous, "Two-Phase Natural Circulation Flow in AP-1000 In-Vessel RetentionRelated ULPU-V Facility Experiments," ICAPP'04, Pittsburgh, PA USA(2004).

[17] J. M. Bonnet, S. Rouge, J. M. Seiler, "Large Scale Experiments for Core Melt Retention: BALI: Corium Pool Thermo hydraulics, SULTAN: Boiling under Natural Convection", OECD/CSNI/NEA Workshop on Large Molten Pool Heat Transfer, Grenoble, France (1994).

[18] S. Rouge, "SULTAN Test Facility for Large-Scale Vessel Coolability in Natural Convection at Low Pressure", Nuclear Engineering \& Design, 169, 185-195 (1997).

[19] M. Barrachin and F. Defoort, "Thermophysical Properties of In-Vessel Corium: MASCA Programme Related Results," Proceedings of MASCA Seminar 2004, Aix-en-Provence, France (2004).

[20] J. M. Seiler et al., "Consequences of Physico-Chemistry Effects on In-Vessel Retention Issue," NURETH-11, Avignon, France(2005).

[21] L. J. Siefken et al., "SCDAP/RELAP5/MOD3.3 Code Manual, Vol. I-V,” NUREG/CR-6150 (2001).

[22] R. J. Park, S. B. Kim, K. Y. Suh, J. L. Rempe and F. B. Cheung, "Detailed Analysis of a Late-Phase Core Melt Progression for the Evaluation of In-Vessel Corium Retention," Nuclear Technology, 156(2006).

[23] Cheynet et al., "Thermosuite," Calphad 26(2), 167 174 (2002).

[24] K. H. Kang, R. J. Park, S. W. Hong, "Thermodynamic Analysis for the Three-layered Melt Pool during the Severe Accidents in the APR1400," NURETH-13, Kanazawa City, Ishikawa Prefecture, Japan(2009).

[25] T. H. Fan and F. B. Cheung, "Modeling of Transient Turbulent Natural Convection in a Melt Layer Solidification" J. of Heat Transfer, 119, 544-552(1997).

[26] F. B. Cheung, "Periodic Growth and Decay of a Frozen Crust over a Heat Generating Liquid Layer," J. of Heat Transfer, 103, 369-375(1981).

[27] R. J. Park, S. M. Choi, S. B. Kim, and H. D. Kim, "Natural Convection Heat Transfer with Crust Formation in the Molten Metal Pool," Nuclear Technology, 127(1), 6680(1999).

[28] R. J. Park, S. M. Choi, S. B. Kim, and H. D. Kim, "Natural Convection Heat Transfer of the Low Prandtl Number Fluid with Solidified Layer Formation," Int. Communications in Heat and Mass Transfer, 25(8), 1065-1074(1998).

[29] S. Globe and D. Dropkin, "Natural Convection Heat Transfer in Liquid Confined by Two Horizontal Plates and Heated From Below, " J. of Heat Transfer, 97, 24-28 (1959).

[30] H. T. Rossby, "A Study of Benard Convection with and without Rotation," J. of Fluid Mech., 36, 309-335(1969).

[31] D. C. Threlfall, "Free Convection in Low-Temperature Gaseous Helium," J. of Fluid Mech., 67, 17-28(1975).

[32] F. Heslot, B. Castaing, and A. Libchabre, "Transitions to Turbulence in Helium Gas," Phys. Rev., A 36, 5870-5873 (1987).

[33] T. Y. Chu and R. J. Goldstein, "Turbulent Convection in a Horizontal Layer of Water," J. of Fluid Mech., 60, 141159 (1973).

[34] Jae-Sun Cho, R. J. Park et al., "Enhanced Natural Convection in a Metal layer Cooled by Boiling Water," Nuclear Technology," 148 (2004). 
[35] S. Cho, K. Y. Suh, C. H. Chung, R. J. Park, and S. B. Kim, "The Effect of Coolant Boiling on the Molten Metal Pool Heat Transfer with Local Solidification," J. of KNS, 32(1), 34-45(2000).

[36] J. L. Rempe, S. A. Chavez, G. L. Allison, G. E. Korth, R. J. Witt, J. J. Sienicki, S. K. Wang, L. A. Stickler, C. H. Heath, and S. D. Snow, "Light Water Reactor Lower Head Failure Analysis," NUREG/CR-5642, EGG-2618(1993).

[37] J. R. Wolf, J. L. Rempe, L. A. Stickler, G. E. Korth, D. R. Diercks, L. A. Neimark, D. W. Akers, B. K. Schuetz, S. A. Chavez, G. L. Thinners, R. J. Witt, M. L. Corradini, and J. A. Kos, "TMI-2 Vessel Investigation Report," NUREG/ CR-6197, EGG-2734(1994).

[38] S.V. Bechta, V.B. Khabensky., S.A. Vitol, E.V. Krushinov, V.S. Granovsky, D.B. Lopukh, V.V. Gusarov, A.P. Martinov, V.V. Martinov, G. Fieg, W. Tromm, D. Bottomley, H. Tuomisto, "Corrosion of vessel steel during its interaction with molten corium. Part 1: Experimental" Nuclear Engineering \& Design, 236, 1810-1829(2006).

[39] S.V. Bechta, V.B. Khabensky., S.A. Vitol, E.V. Krushinov, V.S. Granovsky, D.B. Lopukh, V.V. Gusarov, A.P. Martinov, V.V. Martinov, G. Fieg, W. Tromm, D. Bottomley, H.
Tuomisto, "Corrosion of vessel steel during its interaction with molten corium. Part 2: Model development", Nuclear Engineering \& Design, 236, 1362-1370(2006).

[40] R. J. Park, K. H. Kang, J. T. Kim, K. Y. Lee, and S. B. Kim, "Experimental and Analytical Studies on the Penetration Integrity under External Vessel Cooling," Nuclear Technology, 145(2004).

[41] K. H. Kang, R. J. Park, J. T. Kim, K. Y. Lee, and S. B. Kim, "Thermal Behavior of the Reactor Vessel Penetration under External Vessel Cooling during a Severe Accident," Nuclear Technology, 145(2004).

[42] R. J. Hammersley and R. E. Henry, "Experiments to Address Lower Plenum Response Under Severe Accident Conditions, “EPRI Report TR-103389-V2P1, Vol. 1\&2 (1994).

[43] R. C. Cripps, H. Hirschmann, B. S. Jackel, J. A. Patorski, and H. P. Seifert, "CORVIS Project - State of Progress CORVIS Report," PSI Technical Report TM-49-95-03 (1995).

[44] T. Y. Chu, M. M. Pilch, J. H. Bentz, J. S. Ludwigsen, WY Lu and L. L. Humperies, "Lower Head Failure Experiment and Analyses," NUREG/CR-5582, SAND98-2047, (1999). 